\title{
Comparison of the immune response between local manufactured and commercial inactivated Newcastle Disease Virus vaccine in a challenge trail with field isolated Newcastle Disease Virus
}

A. I. Ahmed ${ }^{1}$; S. M. Odisho ${ }^{2}$ and R. N. Al-Gafari ${ }^{3}$

${ }^{1}$ Animal Resource Department, College of Agriculture, Salahaddin University, Erbil,

${ }^{2}$ Microbiology Department, College of Veterinary Medicine, University of Baghdad,

${ }^{3}$ Microbiology Department, Biotechnology Research Center, Al-Nahrain University, Iraq.

E-mail: ahmed.ahmed1@su.edu.krd

Received: 9/8/2017

Accepted: $24 / 10 / 2017$

Publishing: 28/6/2018

\section{Summary}

Velogenic Newcastle Disease Virus was isolated from broiler chickens in Northern Iraq. An inactivated vaccine was manufactured locally using as seed virus ELD50/ml10 ${ }^{9}$ and then compared with commercial inactivated vaccine in an experimental study which included 120 broiler chicks divided into three groups (G1 unvaccinated control, G2 for commercial vaccine and G3 for local vaccine). The chicks were injected subcutaneously at 3 days old followed by booster Lasota live vaccine eye drop. Indirect ELISA technique was used to estimate the antibody titer from the collected sera of chicks at age 7,17 and 27 days (pre-challenge) and challenged at 31 days old with the same virus. The results indicated that there were significant differences $(\mathrm{P}<0.05)$ between vaccinated group G2 and G3 at $27^{\text {th }}$ day old and showed a high antibody level with high protection percentage compared with the control. G1 which shown no survival, $100 \%$ mortality and severe histopathological lesions, while in G2 and G3 was $43 \%$ and $87 \%$ respectively. Post-challenge antibody titers of survival chicks showed in G3 significantly over the G2 with less severe histopathological lesions. This study concluded that vaccine failure could occur due to factors of the immune status of the host, improper storage of vaccine, improper vaccination and variant pathogenic virus strain. More epidemiological surveillances are required to decide the actual impact of the disease in poultry farms and matching the vaccines.

Keywords: Newcastle Disease Virus, Challenge test, Inactivated vaccine, Histopathology.

\section{Introduction}

Newcastle disease (ND) is one of the most important diseases that affect birds, in particular chickens. The epizootic nature of the disease has caused severe economic losses in the poultry farms worldwide (1). The Newcastle disease virus (NDV) strains pathogenicity can be classified into three pathotypes (velogenic, mesogenic and lentogenic) on the basis of the severity of disease in chickens. Severity is determined by in vivo pathogenicity test parameters, including the mean death time in chicken embryos and the intra-cerebral pathogenicity index in day-old chicks (2). A lethal infection by a velogenic NDV pathotype results in high mortality in chickens. The spread of NDV in chickens routinely vaccinated with NDV vaccines derived from known strains such as Clone 30 or La Sota. Many researchers have reported that the viruses isolated in Korea and
China belong to the VIId sub-genotype of genotype VII in poultry in spite of excessive vaccination programs (3 and 4). They suggested that these VIId isolates are antigenically distinct from the currently available NDV vaccine strains. Alternatively, it is possible that the vaccines are not sufficiently immunogenic to prevent the spread of NDV (5). Some researchers concluded that vaccine produced from virus isolated from previous local NDV outbreak revealed high level of protection (5 and 6). The research was designed to prepare an inactivated vaccine from recently local isolates of NDV and study the efficacy of the vaccine and their protections capacity against the infection with significant level of antibodies to reduce mortality rate.

\section{Materials and Methods}

Local isolated velogenic NDV from poultry flocks was used as seed of virus, with titer of 
$10^{6} \mathrm{HA}$, the inactivation of virus achieved with formalin at a final concentration of $1 / 1000$ were done according to method of Palaya (1991) (7). Efficacy of inactivation of the viruses test: Conducted according to method described by (8) in ECE 10 day old injection with $0.2 \mathrm{ml}$ of the fluid (containing the inactivated virus by formalin) then the harvested embryonic fluid after 5 days and repeating the previous process twice to make sure of the inactivation of the viruses. Then, allantoic fluid was collected, preserved in the refrigerator $\left(4^{\circ} \mathrm{C}\right)$. Inactivated $\mathrm{ND}$ virus was mixed with cofactor oil (Oil Adjuvant), the watery part was prepared (Liquid Phase) by adding $0.01 \%$ of $10 \%$ merthiolate as preservative material to the inactivated allantioc fluid, then mixing well on a magnetic stirrer for two hours. At the same time add the oil phase "Incomplete Freund's adjuvant as water-in-oil emulsion" (7). Physical properties color, Viscosity test, stability of vaccine: were done according to (9). Ten chicks aged five days were immunized with inactivated vaccine subcutaneously and observed for 35 days and clinical sign and gross lesion were recorded to ensure safety of vaccine. One hundred twenty broiler chicks (Ross 308 Breeders) one day old were divided into 3 groups 40 chicks of each in separated boxes. All groups except control were vaccinated with ND Clone 30 (Intervet ${ }^{\circledR}$ ) at 1 day old, at 3 days old the chicks in the second group were vaccinated with $0.5 \mathrm{ml}$ of commercial inactivated ND, the third groups vaccinated with $0.5 \mathrm{ml}$ of field isolate inactivated vaccine subcutaneously followed with Lasota vaccine at 10 days old via ocular route and control left without vaccines.
Experimental chickens were monitored by collecting serum at 7, 17 and 27 days old prechallenge and in 41 days old 10 days postchallenge. Blood samples collected and serum were separated to evaluate the antibody titer then stored at $-20^{\circ} \mathrm{C}$ until use. Antibody titre against NDV in serum was determined by Indirect ELISA technique using ELIZA Kit (Synbiotic kit). Seven chicks taken from each group at 31 days old were housed separately and brood properly and inoculated intra-ocular and intra-nasal with $0.5 \mathrm{ml}$ Local isolated velogenic ND virus contain $10^{9}$ (ELD50)/bird, clinical sign and gross lesion of ND of sick and died birds were recorded, then organ samples (lung as a site of infection) were collected for histopathological study (10 and 11).

\section{Results and Discussion}

The result of safety test revealed no specific symptoms related to ND which confirms the safety of vaccine. This finding agreed with (6) noted that inoculation double dose of inactivated (killed) vaccine via subcutaneous route back of the neck for safety ensuring did not produce side effects. The evaluation of immune response was determined (Table, 1 ) at 7, 17 and 27 days-old chicks pre-challenge the result showed significantly differences in mean \pm SE titer at 27 days-old in vaccinated group (G2 and G3) were 1008 \pm 193 and $2816 \pm 614$ respectively similar finding with (12), also titer produced after immunization with inactivated vaccine produce higher titer after 27 days old, while decline mean \pm SE antibody titer in non-vaccinated control group (G1) was $296 \pm 16.69$.

Table, 1: Response of 31 day old broilers chickens to velogenic Newcastle disease virus challenge (109 ${ }^{9}$ EDDO)

\begin{tabular}{clcccc}
\hline Groups & \multicolumn{1}{c}{ vaccines } & $\begin{array}{c}\text { mean } \pm \text { SE } \\
\text { Titer in }\end{array}$ & $\begin{array}{c}\text { mean } \pm \text { SE } \\
\text { Titer in }\end{array}$ & $\begin{array}{c}\text { mean } \pm \text { SE } \\
\text { Titer in }\end{array}$ & $\begin{array}{c}\text { mean } \pm \text { SE } \\
\text { Titer in }\end{array}$ \\
& & 7 day old & $\mathbf{1 7}$ day old & 27 day old & 41 day old (10pc) \\
\hline Group1 & Unvaccinated Control & $\mathbf{4 2 5 1} \pm \mathbf{1 0 7 8}$ & $\mathbf{9 0 6} \pm \mathbf{3 3}$ a & $\mathbf{2 9 6} \pm \mathbf{1 6}$ b & - \\
Group2 & Commercial Vaccine & $\mathbf{4 2 5 1} \pm \mathbf{1 0 7 8}$ & $\mathbf{8 4 4} \pm \mathbf{1 5 3}$ a & $\mathbf{1 0 0 8} \pm \mathbf{1 9 3}$ b & $\mathbf{2 1 0 6} \pm \mathbf{1 3 3}$ a \\
Group3 & Experimental Vaccine & $\mathbf{4 2 5 1} \pm \mathbf{1 0 7 8}$ & $\mathbf{1 1 4 5} \pm \mathbf{2 1 9}$ a & $\mathbf{2 8 1 6} \pm \mathbf{6 1 4} \mathbf{a}$ & $\mathbf{2 9 8 6} \pm \mathbf{4 1 7} \mathbf{a}$ \\
\hline
\end{tabular}

Small letter indicates significant different $\mathbf{P}<0.05$ in days of age

The mean \pm SE antibody titer of G3 immunized with experimental vaccine $10^{9}$ EID50 $\backslash \mathrm{ml}$ show titer significantly over the G2 immunized with commercial vaccine. This result agreed with (13) who suggested that administrating inactivated vaccine with live vaccine produce higher immunity and for longer period same as Hooper which concluded that inactivated vaccine contained high titer of seed virus and produced higher 
titer 10-14 days after vaccination than inactivated vaccine contain lower titer of seed virus (14). The result of challenge test showed that non vaccinated control group were highly susceptible to challenge $100 \%$ mortality, while G2 group (commercial inactivated vaccine) $43 \%$ survived and G3 group (experimental inactivated vaccine) $87 \%$ survived the mortality in this group return to other causes than NDV shown in (Table, 2). There is X2= 11.25 significant differences among groups in mortality rate: the lowest mortality rates showed in the experiment group. The clinical signs are first recognizable starting at 2 days post-challenge among non-vaccinated or poor protected from virulent NDV. This finding was accepted by (15-18) due to inoculate virus high titer via intra-ocular and intra-nasal the respiratory tract infection preferred the same finding by (19 and 20). The majority of signs are sudden death to high mortality, paralysis, depression, prostration, off feed, respiratory signs, gasping, swelling of eyelid and death started from 4 days while in G2 there is a depression, decrease food intake with mild respiratory signs, death occurred at 6 days post-challenge and in G3 there was a depression, decrease food intake for 2 days then return to normal except one bird dead other cause than NDV, post mortem lesion in scarified chicken appeared conjunctivitis, congested of lung, liver, kidney hemorrhages and ulceration on tip of glands in proventiculus, cecal tonsil and disseminated foci of necrosis in the spleen, same finding proved by (15-18) (Fig.1 and Table, 2).

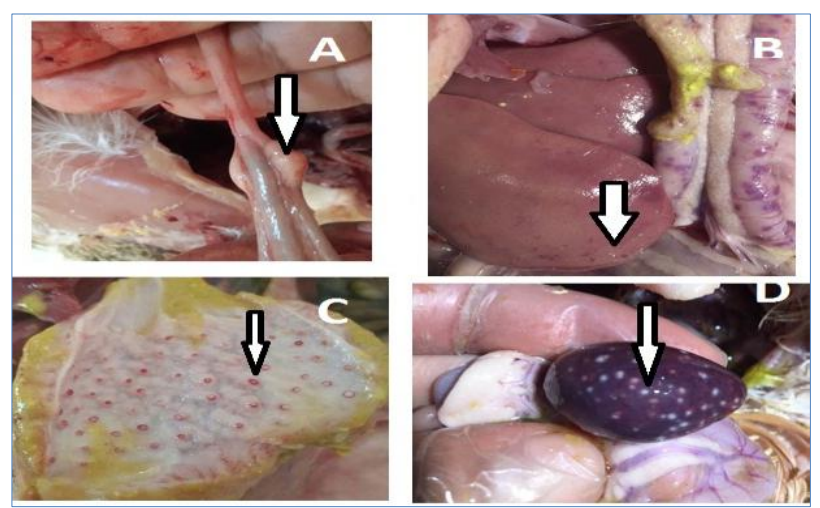

Figure, 1: Gross lesion post-challenge, (A) Cecal Tonsil showing hemorrhage and foci of necrosis (B) Liver appear enlargemed and congested (C) Provinticulus showed petechial hemorrhages and ulceration on tip of glands (D) Spleen shows splenomegaly and foci of necrosis.

Table, 2: Response of 31 day old broilers chickens to velogenic NDV challenge (109 ELD50). Challenge test.

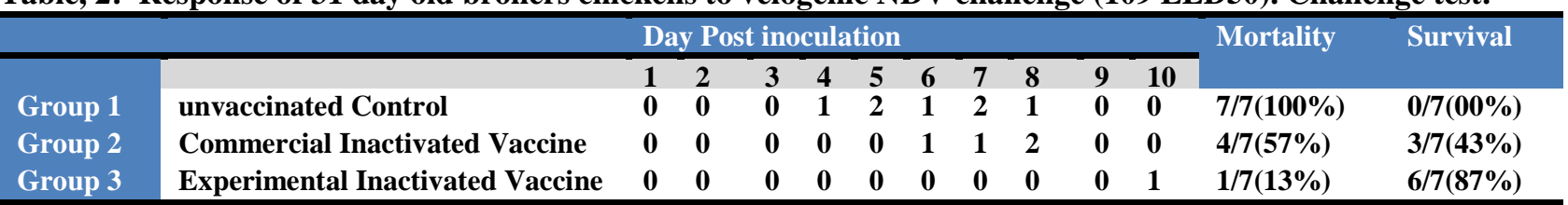

Number of chicks Dead/survival, there is X2=11.25 significant differences among groups in mortality rate the lowest mortality rates in the experiment group

The mean antibody titers were determined and observed. On 41 day old (10 days postchallenge) these values increased significantly and were $(2106 \pm 133$ and $2986 \pm 417$ in (G2 and G3) respectively (Table, 1). The result of histopathological sections, the main changes of lung tissue showed sever pulmonary congestion with hetrophils in the lumen of blood vessels and fibrin networks deposition in the interstitial tissue in control group (Fig. 2 and 3) and G2 (commercial vaccine) (Fig. 4 and 5). The lung showed severe lesion with severe congested blood vessels fibrin networks deposition in the interstitial tissue and odema, compared with G3 (expremintal vaccine) showed only mild congested blood vessels and antrumin lung and mild congestioed dilated sinusoids (Fig. 6 and 7). This study is in agreement with severe lesions observed in birds after experimental with NDV by (21).

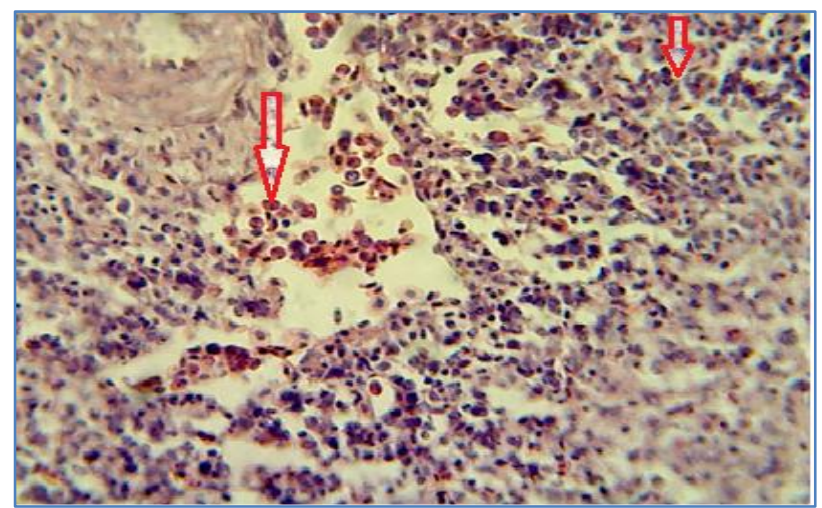

Figure, 2: Section in the lung of unvaccinated infected chicken (control) shows severe congested blood vessels with hetrophils in the lumen of blood vessels and in the interstitial tissue (H\&E stain 400X). 


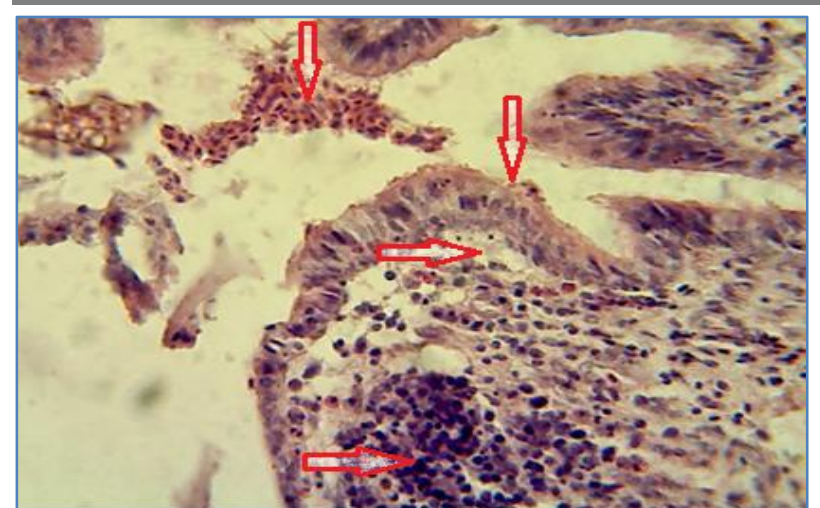

Figure, 3: Section in the lung of infected unvaccinated infected chicken (control) shows mononuclear cells aggregation in the wall of bronchi with $R B C$ in their lumen in addition to erosed epithelial cells (H\&E stain 400X).

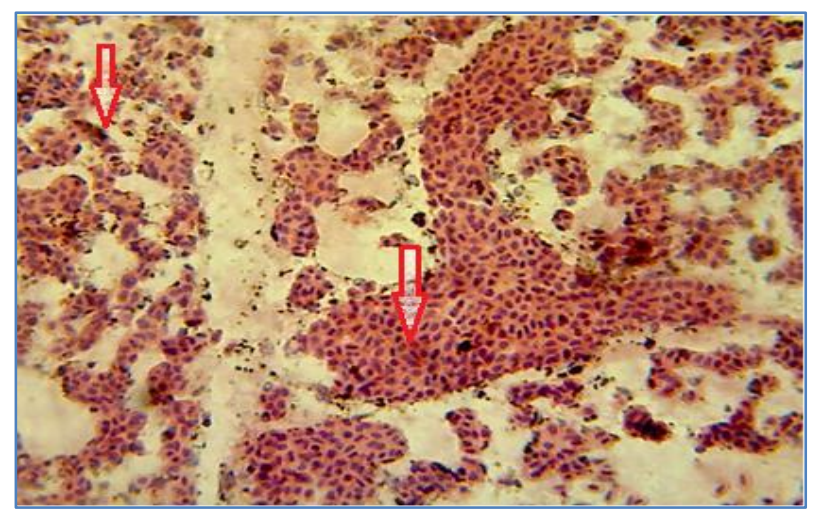

Figure, 4: Section in the lung of infected immunized chicken with commercial inactivated vaccine shows congested antrum (H\&E stain 400X).

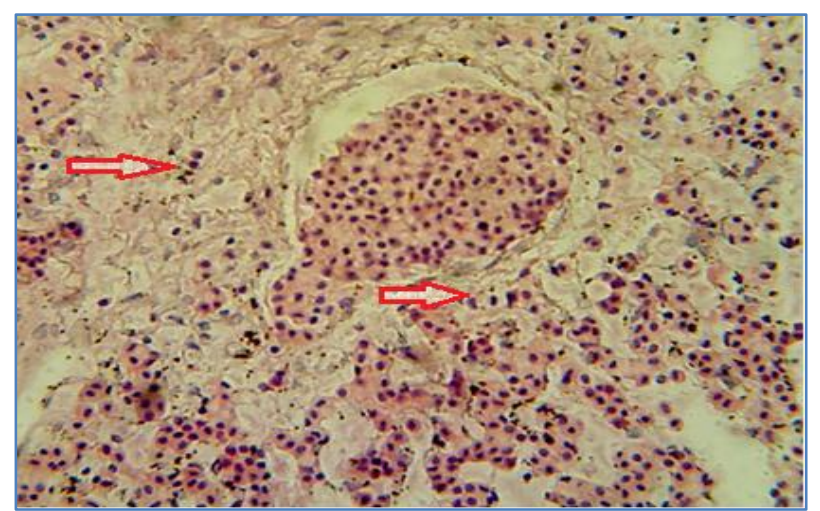

Figure, 5: Section in the lung of infected immunized chicken with commercial vaccine shows fibrin networks deposition in the interstitial tissue (H\&E stain 400X).

The result showed that the comercial vaccine fail to prevent ND clinical sign and gross lesion the same as proved by (22). It has been observed that available ND vaccines fail to protect against morbidity and mortality caused by new variants NDV. Also (23) suggest that NDV variants may be evolved in poultry as a result of suboptimal vaccination (23). OIE proved that regardless of genotype variants circulating NDV strains, all NDV isolates belong to the same serotype. If the vaccination is given correctly, ND vaccines prepared with any NDV should protect poultry from clinical disease and mortality in the event of a virulent challenge (24).

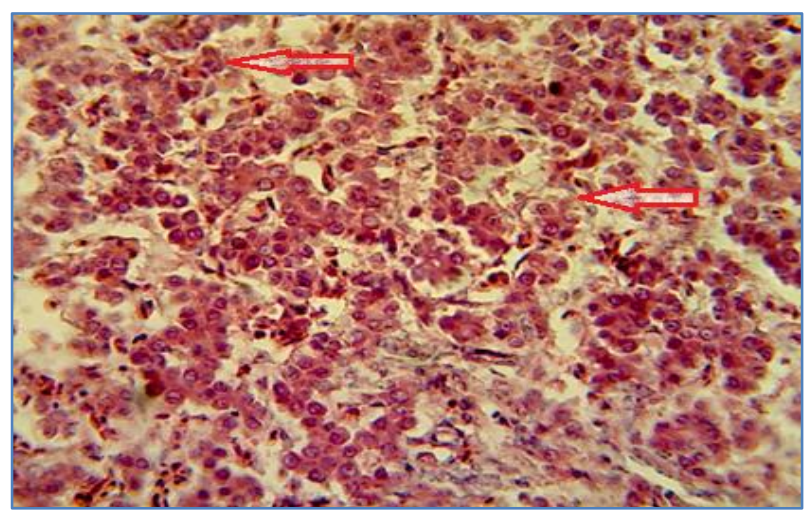

Figure, 6: Section in the liver of infected immunized chicken with local vaccin shows mild congested dilated sinusoids (H\&E stain 400X).

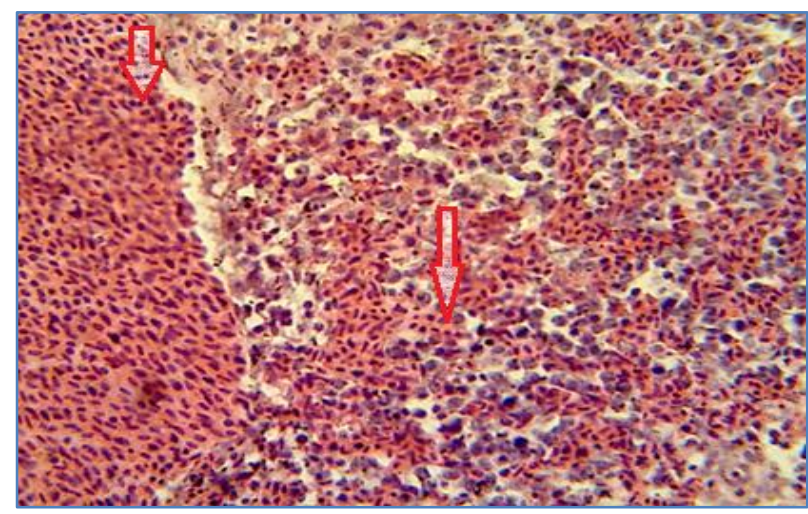

Figure, 7: Section in the lung of infected immunized chicken with local vaccin shows severe congested antrum and blood vessels (H\&E stain 400X).

1. Mayo, M.A. (2002). A summary of taxonomic changes recently approved by ICTV. Arch. Virol., 147:1655-1663.

2. Alexander, D.J. (1988). Newcastle Disease Kluwer Academic Publishers, Pp:147-160. Boston.

3. Liang, R.; Cao, D.J.; Li, J.Q.; Chen, J.; Guo, X.; Zhuang, F.F. and M.X. Duan (2002). Newcastle disease outbreaks in western China were caused by the genotypes VIIa and VIII. Vet. Microbiol., 87:193-203.

4. Yu, L.; Wang, Z.; Jiang, Y.; Chang, L. and Kwang, (2001). Characterization of newly emerging Newcastle disease virus isolates from the people's republic of China and Taiwan. J. Clin. Microbiol., 39:3512-3519.

5. Kapczynski, D.R. and King, D.J. (2005). Protection of chickens against overt clinical 
disease and determination of viral shedding following vaccination with commercially available Newcastle disease virus vaccines upon challenge with highly virulent virus from the California 2002 exotic Newcastle disease outbreak. Vac., 23(26):3424-33.

6. Zahid, A.A.H. and AL-Saeedi, T.A. (2014) Preparation of live attenuated and killed vaccines of Newcastle disease (strain AG 68) and immunity evaluation Al Qadsiya Vet. S. J., 13(1):30-36

7. Palaya, V. (1991). Manual for the production of Mareks disease, Gumboro disease and inactivated Newcastle disease vaccines, animal production and health paper 89 . Food and Agriculture organization Rome, Pp:2960.

8. Allan, W.H.; Lancaster, J.E. and Toth, B. (1978). Newcastle Disease Vaccines, their Production and Use. Food and Agriculture Organization of the United Nation, Rome.

9. Stone, H.D.; Brugh, M.; Hopkins, S.R.; Youder, H.W. and Beard, C.W. (1978). Preparation of inactivated oil emulsion vaccines with avian viral or mycoplasma antigens. Avian Dis., 22(4):666-674.

10. Benyeda, Z.; Szeredi, L.; Mató, T.; Süveges, T.; Balka, G.; Abonyi-Tóth, Z.; Rusvai, M. and Palya, V. (2010). Comparative histopathology and immunohistochemistry of QX- like, Massachusetts and 793/B serotypes of infectious bronchitis virus infection in chickens, J. Compar. Pathol., 143:276-283.

11. Luna, L.G. (1968). Manual of histological staining method of armed forces instant of pathology. $3^{\text {rd }}$ ed. McGraw. Hill Book Co. Pp:3.

12. Sally, E. G. (2002). A basic laboratory manual for the small-scaie production and testing of I-2 Newcastle disease vaccine. Australian Center for International Agricultural Research. ISBN 974-7946-26-2.

13. Rahman, M.M.: Bari, A.S.: Giasuddin, M.: Islam, M. R.: Alam, J. and Sil, G.C. (2002). Evaluation of maternal and humoral immunity against Newcastle disease virus in chicken. Int. J. Poult. Sci., I(15):161-163.

14. Hooper, P.T.; Hanson, E.; Young, J.G.; Russell, G.M. and Dellaporta, A.L. (1999). Lesions in the upper respiratory tract in chickens experimentally infected with
Newcastle disease virus isolated in Australia. Aust. Vet. J., 77: 50-51.

15. Brown, C.; King, D.J. and Seal, B.S. (1999). Pathogenesis of Newcastle disease in chickens experimentally infected with viruses of different virulence. Vet. Pathol. 36:125132.

16. Kommers, G.D.; King, D.J.; Seal, B.S. and Brown, C.C. (2003). Pathogenesis of chicken-passaged Newcastle disease viruses isolated from chickens and wild and exotic birds. Avian Dis., 47:319-329.

17. Susta, L.; Miller P.; Afonso C. and Brown, C. (2010). Clinicopathological characterization in poultry of three strains of Newcastle disease virus isolated from recent outbreaks. Vet. Pathol., 48(2):349-360.

18. Wakamatsu, N.; King, D.J.; Kapczynski, D.R. (2006). Experimental pathogenesis for chickens, turkeys, and pigeons of exotic Newcastle disease virus from an outbreak in California during 2002-2003. Vet. Pathol., 43:925-933.

19. Alexander, D.J. and Senne, D.A. (2008). Newcastle disease and other avian paramyxo viruses. In: A laboratory manual for the isolation, identification and characterization of avian pathogens,ed. Dufour-Zavala L, Senne DA, Glisson JR, et al., $5^{\text {th }}$ ed., Pp:135141. American Association of Avian Pathologists, Athens, GA.

20. Kotani, T.; Odagiri, Y.; Nakamura, J. and Horiuchi, T. (1987). Pathological changes of tracheal mucosa in chickens infected with lentogenic Newcastle disease virus. Avian Dis., 31:491-497.

21. Igwe, A.O.; Ezema, W.S.; Eze, D.C. and Okoye, J.O.A (2014). Experimental Velogenic Newcastle disease can be very severe and viscerotropic in chickens but moderate and neurotropic in guinea fowls. Int. J. Poult. Sci., 13(10):582-590.

22. Bulbule, N.R.; Madale, D.S.; Meshram, C.D.; and Pardeshi, R.B. (2015). Virulence of Newcastle disease virus and diagnostic challenges. Adv. Anim. Vet. Sci., 3(5):14-21.

23. Jeon, W.J.; Lee, E.K.; Lee, Y.J.; Jeong, O.M.; Kim, Y.J.; Kwon, J.H. and Choi, K.S. (2008). Protective efficacy of commercial inactivated Newcastle disease virus vaccines in chickens against a recent Korean epizootic strain. J. Vet. Sci., 9:295-300. 
24. OIE. (2008). World Organization for Animal Health. Manual of Diagnostic Tests and
Vaccines for Terrestrial Animals. $6^{\text {th }}$ ed. Paris, France. Pp:576-589.

\section{مقارنة الاستجابة المناعية بين لقاح مرض النيوكاسل المقتول المنتج محلياً مع التجاري بالتحدي مع فيروس}

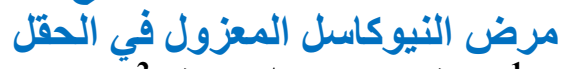

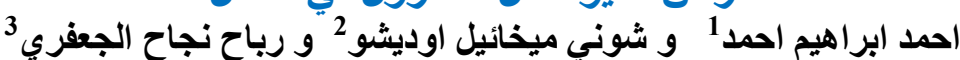

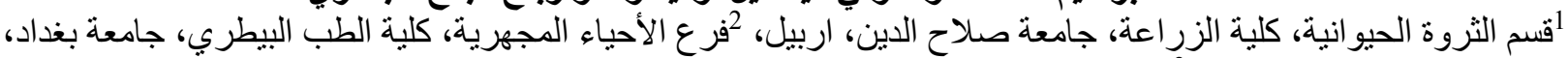

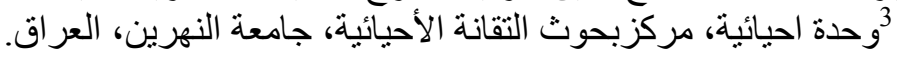

E-mail: ahmed.ahmed1@ @u.edu.krd

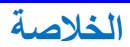

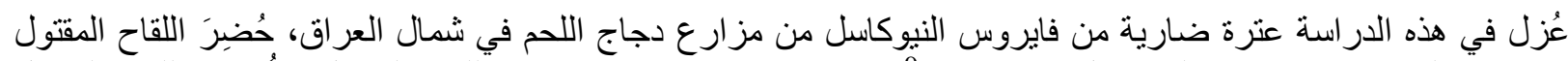

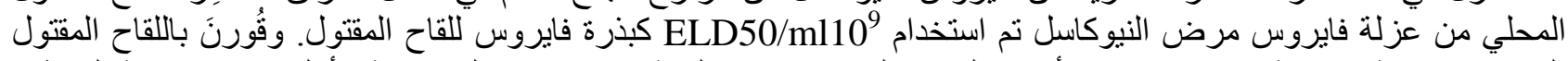

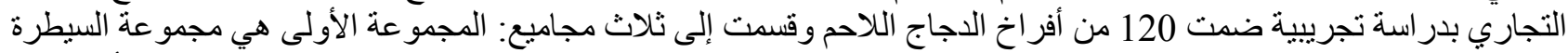

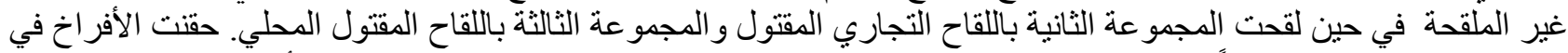

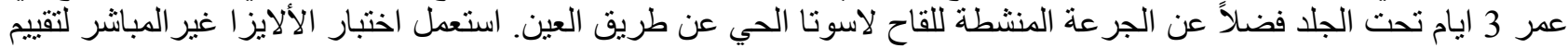

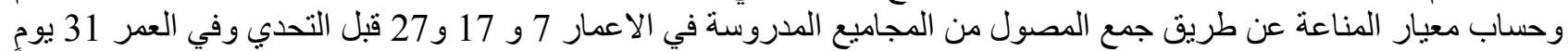

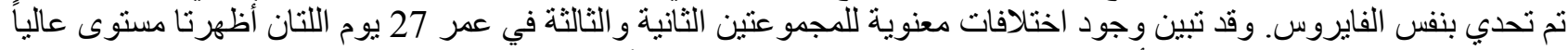

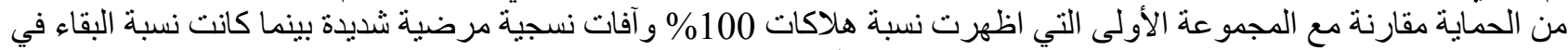

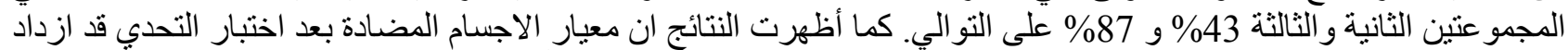

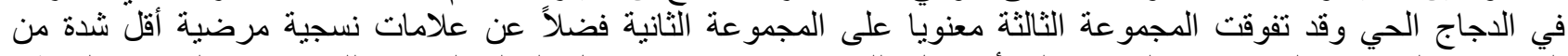

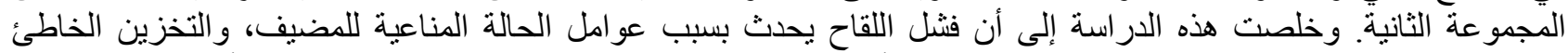

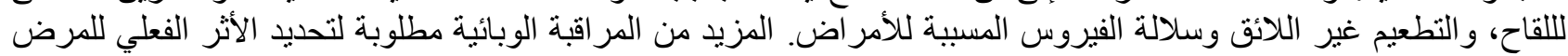

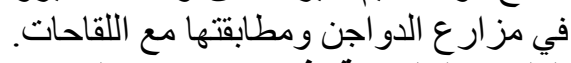
الكلمات المفتاحية: فايروس نيوكاسل، اختبار التحدي،اللقاح المقتول، الفحوصات النسجية المرضية. 